Progression-free survival

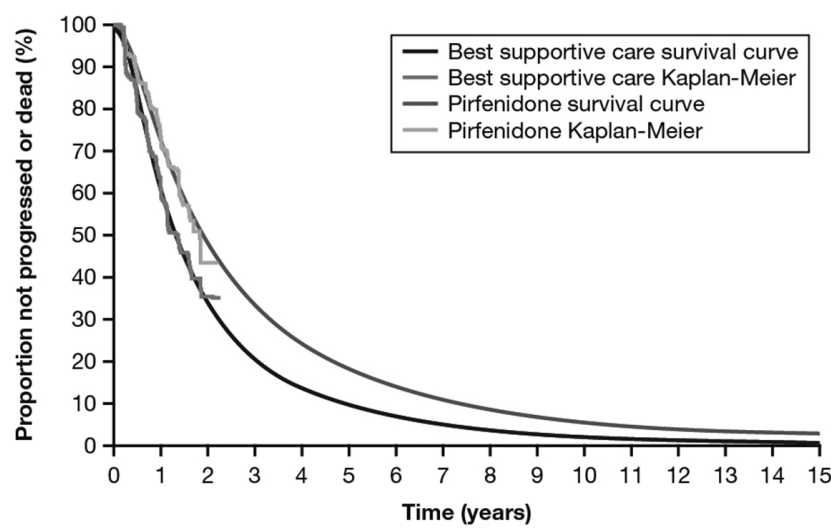

Overall survival

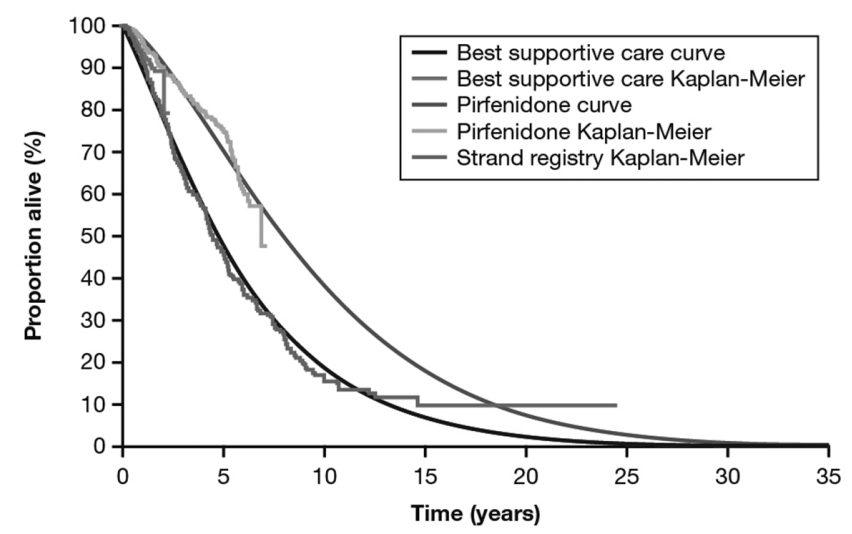

Abstract S107 Figure 1 Progression-free and overall survival Kaplan-Meier and curves

\section{S108 EFFECT OF BASELINE FVC ON DECLINE IN LUNG FUNCTION WITH NINTEDANIB IN PATIENTS WITH IPF: RESULTS FROM THE INPULSIS ${ }^{\circledR}$ TRIALS}

${ }^{1} \mathrm{M}$ Kolb, ${ }^{2} \mathrm{~T}$ Kimura, ${ }^{2} \mathrm{~S}$ Stowasser, ${ }^{2} \mathrm{C}$ Hallmann, ${ }^{3} \mathrm{~L}$ Richeldi. ${ }^{1} \mathrm{McMaster}$ University, Hamilton, Canada; ${ }^{2}$ Boehringer Ingelheim Pharma GmbH \& Co. KG, Ingelheim Am Rhein, Germany; ${ }^{3}$ National Institute for Health Research Southampton Respiratory Biomedical Research Unit and Clinical and Experimental Sciences, University of Southampton, Southampton, UK

\subsection{6/thoraxjnl-2015-207770.114}

Introduction The two replicate, randomised, placebo-controlled, 52-week Phase III INPULSIS ${ }^{\circledR}$ trials assessed the efficacy and safety of nintedanib $150 \mathrm{mg}$ twice daily (bid) in patients with idiopathic pulmonary fibrosis (IPF). Patients with forced vital capacity (FVC) $\geq 50 \%$ predicted were included. The primary endpoint, the annual rate of decline in FVC, was significantly reduced in the nintedanib group compared with placebo in both trials, consistent with a slowing of disease progression. Key secondary endpoints were time to first acute exacerbation and change from baseline in St. George's Respiratory Questionnaire total score, both over 52 weeks. In a pre-specified subgroup analysis of patients with baseline $\mathrm{FVC} \leq 70 \%$ versus $>70 \%$ predicted, the treatment effect of nintedanib on decline in FVC was consistent in both subgroups.

Methods A post-hoc subgroup analysis of patients with baseline FVC $>90 \%$ versus $\leq 90 \%$ predicted was undertaken using pooled data from the INPULSIS ${ }^{\circledR}$ trials to investigate whether patients with marginally impaired FVC receive the same benefit from nintedanib.

Results 274 patients (nintedanib 166, placebo 108) had baseline FVC $>90 \%$ predicted and 787 patients (nintedanib 472, placebo 315 ) had baseline FVC $\leq 90 \%$ predicted. There was no significant treatment-by-subgroup interaction for the primary endpoint $(\mathrm{p}=0.5300)$; in patients with baseline $\mathrm{FVC}>90 \%$ predicted, the adjusted annual rate of decline in FVC was $-91.5 \mathrm{~mL} /$ year with nintedanib and $-224.6 \mathrm{~mL} /$ year with placebo (difference: $133.1 \mathrm{~mL} /$ year [95\% CI: 68.0, 198.2]) while in patients with baseline FVC $\leq 90 \%$ predicted, it was $-121.5 \mathrm{~mL} /$ year with nintedanib and $-223.6 \mathrm{~mL} /$ year with placebo (difference: $102.1 \mathrm{~mL}$ / year [95\% CI: 61.9, 142.3]). Consistent results were observed for changes from baseline in FVC over time (Figure 1). No significant treatment-by-subgroup interaction was observed for the key secondary endpoints. The frequency of adverse events and serious adverse events was comparable between the treatment arms of each subgroup.

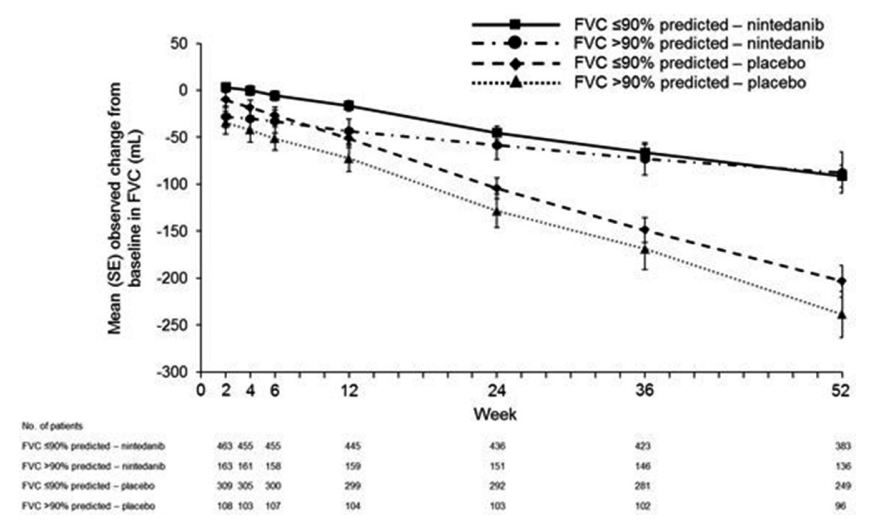

\section{Abstract S108 Figure 1}

Conclusion In a subgroup analysis of pooled data from the INPULSIS $^{\circledR}$ trials, nintedanib $150 \mathrm{mg}$ bid slowed the decline in lung function in patients with IPF independent of degree of lung function impairment at baseline, suggesting that patients with marginally impaired FVC also benefit from treatment with nintedanib.

\section{S109 EFFECT OF CONTINUED TREATMENT WITH PIRFENIDONE FOLLOWING A CLINICALLY MEANINGFUL DECLINE IN PERCENT PREDICTED FORCED VITAL CAPACITY IN PATIENTS WITH IDIOPATHIC PULMONARY FIBROSIS (IPF)}

${ }^{1} \mathrm{PW}$ Noble, ${ }^{2} \mathrm{C}$ Albera, ${ }^{3} \mathrm{WZ}$ Bradford, ${ }^{4} \mathrm{U}$ Costabel, ${ }^{5}$ Glaspole, ${ }^{6} \mathrm{MK}$ Glassberg, ${ }^{7} \mathrm{~L}$ Lancaster, ${ }^{8} \mathrm{DJ}$ Lederer, ${ }^{3} \mathrm{Z}$ Lin, ${ }^{9} \mathrm{CA}$ Pereira, ${ }^{10} \mathrm{JJ}$ Swigris, ${ }^{11} \mathrm{D}$ Valeyre, ${ }^{12} \mathrm{SD}$ Nathan. ${ }^{1}$ Cedars Sinai Medical Center, Los Angeles, USA; ${ }^{3}$ University of Turin, Turin, Italy; ${ }^{3}$ InterMune Inc (A Wholly Owned Roche Subsidiary), Brisbane, USA; ${ }^{4}$ Ruhrlandklinik, Essen, Germany; ${ }^{5}$ Alfred Hospital, Melbourne, Australia; ${ }^{6}$ University of Miami Miller School of Medicine, Miami, USA; ${ }^{7}$ Vanderbilt University Medical Center, Nashville, USA; ${ }^{8}$ Columbia University, New York, USA; ${ }^{9}$ Paulista School of Medicine, Federal University, Sao Paulo, Brazil; ${ }^{10}$ National Jewish Health, Denver, USA; ${ }^{11}$ Avicenne Univsersity Hospital, Bobigny, France; ${ }^{12}$ Inova Fairfax Hospital, Falls Church, USA

10.1136/thoraxjnl-2015-207770.115 